DIW BERLIN

Discussion

Papers
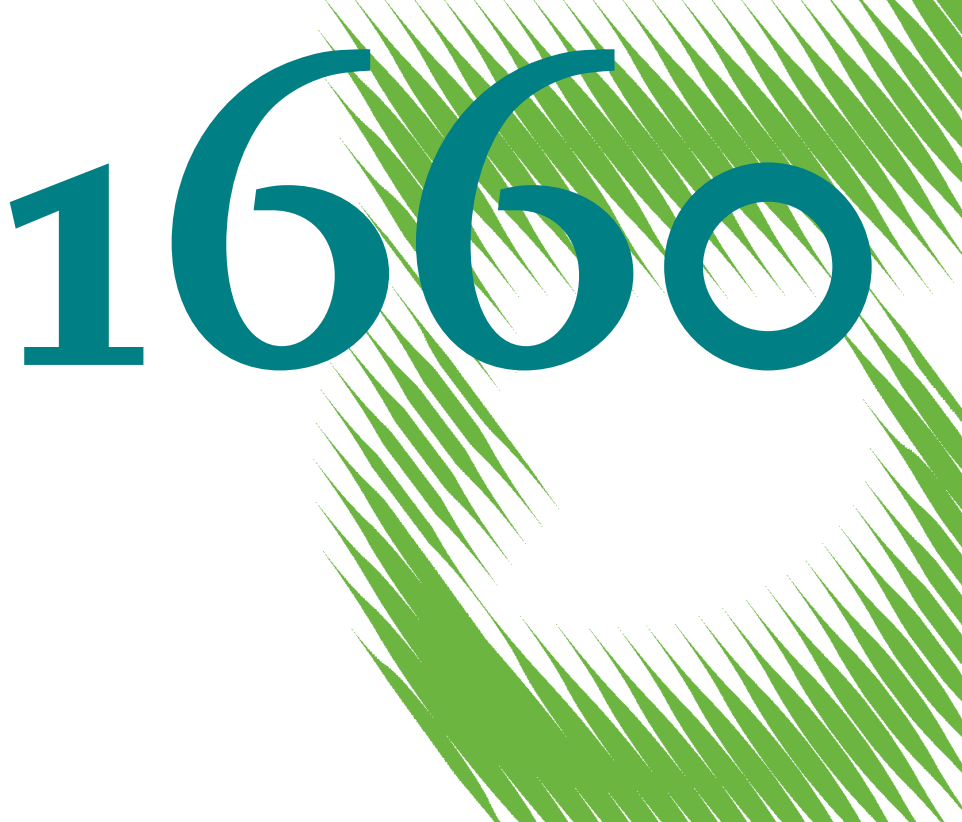

1111
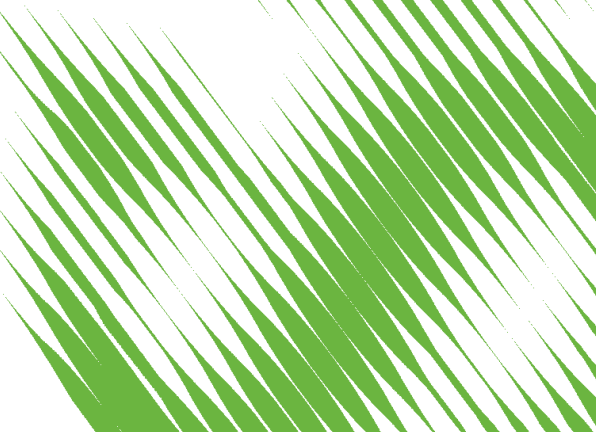

11
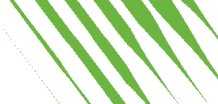

MIMMMMMMMM

The Hukou Impact on the Chinese Wage Structure 
Opinions expressed in this paper are those of the author(s) and do not necessarily reflect views of the institute.

IMPRESSUM

(C) DIW Berlin, 2017

DIW Berlin

German Institute for Economic Research

Mohrenstr. 58

10117 Berlin

Tel. +49 (30) $89789-0$

Fax +49 (30) $89789-200$

http://www.diw.de

ISSN electronic edition 1619-4535

Papers can be downloaded free of charge from the DIW Berlin website:

http://www.diw.de/discussionpapers

Discussion Papers of DIW Berlin are indexed in RePEc and SSRN:

http://ideas.repec.org/s/diw/diwwpp.html

http://www.ssrn.com/link/DIW-Berlin-German-Inst-Econ-Res.html 


\title{
The Hukou Impact on the Chinese Wage Structure
}

\author{
Christian Dreger, Yanqun Zhang ${ }^{1}$
}

\begin{abstract}
Faster urbanization plays a key role in the Chinese economic transformation. However, at the Lewis turning point, the hukou institution constitutes a serious risk to the process, as it restricts the access of migrants to public services offered by cities. To attract further migration, firms started to accept a premium on top of the wage. Thus, the social discrimination introduced by the hukou system is partially compensated by the reactions of market participants, as migrant workers receive additional pay. Based on huge cross sections of private households, this paper provides insights into the size and the evolution of the wage premium. After controlling for standard wage determinants, such as sex, education, experience and ownership of firms, we find that the premium amounts to 7 percent of the hourly wage. Because of the premium, the share of non-wage labor costs is on the rise, especially for low-skilled migrants. To avoid further distortions and reduce inefficiencies, the hukou status should be unified. Migrants should obtain urban hukou as long as they live in cities. They should keep their land use rights when they are in the rural areas. Otherwise, the system could constitute a significant barrier for further urbanization. The removal of institutional bias could restore the link between wages and productivity and improve the allocation of labor.
\end{abstract}

Keywords: Chinese economic transformation, wage premium, hukou reform JEL: J30, R23, C23

\footnotetext{
${ }^{1}$ Dreger: German Institute for Economic Research (DIW Berlin), cdreger@diw.de, Zhang: Chinese Aca-demy of Social Sciences (CASS), Beijing, China, yqzhang@cass.org.cn.
} 
The Chinese economic transformation stands at its crossroads. Former policies focused on high GDP growth driven by exports and investment, but at the expense of rising overcapacities in many industrial sectors and increasing government debt. To address the imbalances, the strategy has been modified in recent years. Instead of export- and investment-led growth, the future evolution will be based on a faster expansion of services and consumption of private households. This may strengthen the role of China for regional market integration in Asia, can improve the resistance of the economy against global shocks and may contribute to ecofriendly and socially inclusive growth. According to the five-year plan of the government, the transformation is underpinned by further urbanization. Larger cities generate economies of scale, due to specialization, information spillovers, broader labor markets and the clustering of firms. It is found that real income per worker is an inverted $U$-shaped function of city employment, with the peak shifting out as industrial composition moves from manufacturing towards services (Au and Henderson, 2006a and b). Productivity losses from undersized Chinese cities fall in a range between 10 and 35 percent, depending on whether the cities are 30 or 50 percent of the optimum size (Yusuf and Nabeshima, 2006). Metropolitan areas can also boost productivity by a faster reduction of workers in agriculture, as their shares are particularly high in lowincome areas. As 30 percent of the workers are employed in the agricultural sector, the urbanization potential is still enormous. The urbanization rate, i.e. the share of population in urban areas to total population already increased from 20 (1980) to 56 percent by the end of 2015. On average, 40 percent of the citizens have urban hukou rights, and the dispersion is large across cities. By 2020, the urbanization rate will increase to 60 percent, as measured by the hukou status. To accomplish the target, one hundred million rural workers will have to migrate. In only two decades, China will have 230 cities with more than 1 million inhabitants, compared to 35 cities in Europe (United Nations, 2014).

Urbanization is driven by net migration from rural to urban areas. Starting from the mid-1980s, the surplus of rural labor contributed to the emergence of industrial sectors in export-oriented coastal regions with wages near the subsistence level (Chang, 1994). During this process, China has become the low-cost workbench of the world economy and may have contributed to the global decline of inflation (Côté and de Resende, 2008). During the last years, however, accelerating wages in urban and rural areas have outpaced productivity gains, albeit from low initial levels. Strong wage hikes could be interpreted as a signal that China reached the Lewis turning 
point (Zhang, Yang and Wang, 2011) or will cross it over the next few years (Das and N'Diaye, 2013). A further indication for this claim is the convergence of wages between skilled and nonskilled workers (Cai and Du, 2011). This result is reinforced by the fast acceleration of minimum wages (Dreger, Kosfeld and Zhang, 2016). Beyond the Lewis turning point, labor will be increasingly scarce. Therefore, high wage growth is expected even in the period ahead. In contrast, Golley and Meng (2011) argued that the pool of underemployment in rural areas is still large. Hence, the removal of policy-induced barriers to migration and measures to raise the length of the stay in cities could foster urbanization, even in case of moderate wage increases. Labor shortages might be also caused by demographic trends, as the labor force will continue to decline.

The hukou institution constitutes an impediment for urbanization, and it is more serious at the Lewis turning point. As holders of non-urban hukou rights have limited access to public services offered by cities, the system generates disincentives for rural workers to migrate. To stimulate further migration, laborers need to be compensated. Besides a gradual expansion of social security and discounts on the purchase of certain consumer goods, firms started to offer a premium on top of the wage. Thus, the social discrimination attributed to a different hukou status is partially offset by the reactions of market participants, as migrants receive additional pay. Based on huge cross sections of private households, this paper provides first evidence into the size and the evolution of the wage premium. After controlling for the standard wage determinants, such as sex, education, experience and ownership of firms, we find that the premium amounts to 7 percent of the hourly wage. Because of the premium, the share of nonproductivity related labor costs is on the rise, especially for low-skilled migrants. To avoid further distortions of the wage structure, hukou reforms should be on the agenda.

The rest of the paper is organized as follows. Section 2 provides a review of the literature on wage determination with special emphasis on the hukou impact. Recent reforms of the hukou system are discussed in Section 3. Empirical evidence is based on different waves of the Chinese Household Income Panel (Section 4). Section 5 holds the results. Policy conclusions are offered in Section 6.

\section{Wage determination and hukou status}

Microeconomic determinants of wages are usually investigated by means of Mincerian wage regressions, see Naughton (2007) for a recent survey. The aim is to identify suitable variables 
to explain the heterogeneity of wages across workers. Besides education and professional experience, personal factors may include sex, age, ethnicity, membership in the communist party or the hukou status. In addition, employer characteristics might be relevant, such as private or public ownership, the industrial sector or the firm size. Macroeconomic conditions like the state of the business cycle or inflation could also affect wages. However, in a cross section they are embedded in the constant term, as they are identical across workers. They could be interpreted as ordinary regressors, if some variability is introduced, for example, by adding a regional dimension.

The results obtained from the wage analysis are broadly in line with international findings. For instance, male workers generally receive higher wages than females and a large part of the differential cannot be explained by personal characteristics, i.e. is related to gender discrimination (Liu, Xi and Zhang, 2000). The deeper the market-oriented reforms in the work unit under consideration, the wider tends to be the wage gap (Zhang, 2004). The returns to education increased tremendously after the turn-of-the-century, notably at the high education levels, see Zhang, Zhao, Park and Song (2005). The rewards from tertiary and higher education appear to be much higher than for secondary schooling and might be affected by an increasing demand of skilled labor and the presence of foreign and joint-venture firms in the Chinese markets, see Yang (2005). Fu and Ren (2010) reported that the gap of return to education among people with different hukou status increases as years of schooling decrease, and reaches its peak in primary education.

According to many researchers, the hukou system is a crucial factor to explain the rural-urban income divide, see Liu (2005) among others. However, so far there is no consensus on how the hukou status affects wage inequality between urban hukou workers and migrants. Some researchers suggested that the stigma of being without urban hukou may lead to unequal pay for migrants in cities, even if they hold similar jobs than urban workers. Meng and Zhang (2001) argued that most of the difference in educational attainment and wages between workers equipped with urban hukou and migrants cannot be explained by productivity-related differences between the two groups. Hence, urban residents are favorably treated and their migrant counterparts are discriminated.

Other scholars stressed that rural migrants are paid less mainly because they have low productivity-related attributes. For instance, migrants from the rural areas are often not well educated. Based on a case study for Tianjin, the returns to education appear to be much larger for 
workers with urban hukou than for migrants from rural areas (Lu and Song, 2006). For Zhang and Wu (2017), lower earnings of rural migrants are mainly anchored in occupational segregation. Workers are sorted into different occupations according to their hukou status and other characteristics. The degree of segregation differs across sectors and is stronger for government agencies and public enterprises.

\section{The hukou system and recent reforms}

The hukou system discriminates migrants working in cities. Households with urban hukou have better social security, health insurance and job opportunities than rural counterparts. Migrants are excluded from many public jobs and have limited access to social insurance and other public services such as low rent housing. Therefore, savings to buffer unforeseen expenditures are higher for migrants than for persons with urban hukou (Dreger, Wang and Zhang, 2015). If migrants become sick, they have little choice but to return to the home villages, as their rural medical insurance is often not valid in different provinces. In Beijing and other cities, they often need to pay a fee for their children to go to public schools. Schools specifically for migrant children are also available. Furthermore, children might attend schools in the rural areas, while living with their grandparents. However, the children become seriously disadvantaged, as the schools usually have low quality. The left-behind children are estimated to be about 9 millions. It is reported that more than 80 kinds of welfare are attached to a Beijing hukou. According to a recent survey of private households in Shanghai, one third of the respondents indicated they would not like to live next door to a migrant, against one-tenth who said they would rather not live next to a poor person (Economist 2014, Apr 19).

The hukou system was initially established after the communist revolution to control migration from rural to urban areas (Cheng and Selden, 1994). Starting with the economic reforms and the abolition of large and inefficient agricultural communes, the mobility barriers have been gradually reduced (Chan and Buckingham, 2008). While migrants from the rural areas are allowed to work in cities, they do not have urban hukou, as they are treated as temporary residents. Many Chinese still live outside their officially registered regions and under far less eligibility to public services. Recent reforms replaced the old system of an agricultural and nonagricultural hukou with a status based on the location of permanent residence. The inheritance of the hukou status has been broadened to allow the succession through the lines of father and mother to correct the former disadvantage against women. Local governments obtained 
the control in deciding the levels of hukou and non-hukou migration with respect to their administrative jurisdictions, including the possibility of using full hukou rights as a measure to raise fiscal revenues. For example, firms can receive certain hukou quota for their workers in Beijing, if their taxes exceed a threshold level. Household surveys indicate that the decision to migrate is indeed affected by the availability of social rights in the place of destination. A person living close to a county-town where social services are available is much more likely to migrate to this location (Lee and Meng, 2009).

Although rural hukou is far less comprehensive, support to respective reforms is not enthusiastic, as the relative values of rural and urban hukou changed over time (Chen and Fan, 2016). If migrants obtain urban hukou, they would lose rural hukou, i.e. the right to a small patch of farmland and a residential plot in their village of registration. The benefits tied to rural hukou are considered increasingly valuable. Thus, many migrants are opting to straddle and circulate between the city and the countryside rather than giving up their rural hukou. The competitive advantage of urban hukou declined as basic public services are gradually expanded to all citizens. Several cities started to adjust social programs, aiming at including migrants into urban social welfare, independently of the hukou status. Households registered in rural areas receive discounts of 13 percent of the sale price on certain white consumer products, such as TV, refrigerators and washing machines. These policies aim to reduce the discrimination caused by the hukou system. However, they might undermine the signaling function of prices and wages in an economy. Scarce ressources may not be allocated to the optimal purposes, implying losses in efficiency.

\section{$4 \quad$ Data on urban workers and migrants}

Evidence is based on huge microeconomic datasets gathered by the Chinese Household Income Project (CHIP) in collaboration with National Statistical Bureau. The CHIP is designed and implemented to measure the distribution of income and related economic factors in urban and rural areas (Li, 2009). Information is available on sociodemographic characteristics like sex, family status, age and ethnicity, education, social security, employment status, professional experience and measures to describe the conditions of the working contract, labor income and working time. The CHIP provides distinct samples of urban households, migrants and rurals, selected from larger samples drawn by the National Statistical Bureau. Migrants refer to those whose household head has rural hukou and live in cities for more than half a year. It should be 
noted that the CHIP survey cannot be extrapolated to the entire economy, as no expansionary factors are provided.

Data are collected through questionnaires conducted at the individual household level. Since a panel structure is not provided, households cannot be studied over time. Instead, the most recent waves of the CHIP are considered for the analysis, i.e. 2007 and 2013. Although only 6 years have been passed between the surveys, the differences can be striking, as the transformation of the Chinese economy occurs very fast. While urban households and migrants are of similar size in the first period (4.700 and 3.600 workers, respectively), migrants are largely underrepresented in the second. Suitable information is reported for 6.800 urban workers, but only for 1200 migrants. Therefore, the migrants are merged with rural households, if the rurals have indicated their willingness to migrate over the next year. The extended migrant sample includes data for 5.600 workers. As the questionnaire did not change substantially between the waves, the cross sections can be investigated with almost the same set of explanatory factors. While the concrete measurement of variables has changed in some cases, the differences remain minor.

\section{$5 \quad$ Wage regressions for urban households and migrants}

Hourly wages are preferred over labor income as dependent variable. Income gaps might be misinterpreted due to different working times between the groups. Migrants usually worked longer than urbans, especially in the first period. The hourly wage is obtained by dividing annual labor income by annual working hours.

-Table 1 about here-

Several features of the wage development are worth to note. In 2013 , hourly wages of urban workers exceeded those of migrants by 28 or 15 percent, as measured by the arithmetic mean or the median, respectively. Although the difference is substantial, it has been much larger in the older wave. Over the recent years, wages have increased much faster for migrants an rurals than for urbans. The rise is especially strong in the low wage segment, where migrant wages exceed the urban benchmark at the 0.1 percentile. The pattern can foster the transfor- 
mation towards consumption led growth, but might also point to serious shortages of laborers willing to migrate.

On average, migrants are 6 years younger than urban workers, and the share of women is lower in their group (Table 2). They are less educated than urban employees, and the gap did not narrow between the waves. They have lower professional experience and are more engaged in short term working contracts, especially in the second sample. However, even half of the urban laborers are working without a permanent or long term contract. Only 7 percent of migrants (2013) are employed in public enterprises. While the characteristics of urban workers are rather similar across the waves, some shifts can be observed for the migrants. Most striking, the professional experience more than doubled. Given that the CHIP survey is representative for the entire population to some extent, the development might indicate longer migration stays in cities. By investigating the 2007 wave, Zhang, Sharpe, Li and Darity (2016) argued that differences in educational attainment, work experience and the distribution with respect to industry, occupation and ownership of firms account for most of the wage differential between urbans and migrants.

-Table 2 about here-

Wages are explained by individual worker and firm characteristics, including sex, age, education, professional experience, the duration of the working contract, industrial sector and the ownership of the firm. Age, education (schooling) and work experience are measured in years and taken in logs. As usual, the squared term is included for age to take potential nonlinearities into account. If the linear effect is positive, but the quadratic one negative, wages increase with age, but less than proportional. Other variables are defined as $(0,1)$ dummies. Sex is equal to 0 for women. Contract is 0 for permanent and long term contracts. Ownership is 0 in case of state-owned firms, and industry is 0 for firms in agriculture, energy and mining and manufacturing. If these conditions are not met, the respective variables are equal to 1 . Firm size refers to the number of employees in the work unit of the employer. It is defined as a continuous variable in the second sample, but as a categorical one in the first. Higher values reflect larger firm size. Other explanatories, such as the marital status, family size, membership in the communist party and ethnicity appear to be clearly insignificant. Due to the presence of outliers, 
quantile regression techniques are preferred, where the sum of absolute deviations from the median is minimized.

-Table 3 about here-

Overall, the regression results appear to be reasonable (Table 3). Earnings disadvantages are notable for women, especially for migrant women, and the degree of discrimination increased in both groups in the transformation towards a market-based economy. Older workers receive a higher hourly pay, but the increase is less than proportional. Although the standard errors are quite large, the seniority principle might have become slightly less relevant in the second period. More education and experience are rewarded in terms of an increase in wages. In particular, a 1 percent increase in the years of schooling rose the wage by more than 0.3 percent in 2007. While the gains have been similar for urban workers and migrants in the first period, they show divergence in the second. While the elasticity doubled for urbans, it halved for migrants. Therefore, migrants have lower incentives to invest in human capital formation. This can cause serious obstacles in the creation of an innovation driven economy. Furthermore, wages increase with the duration of the labor contract, especially for urbans. Conversely, if the urbans enter temporary job arrangements, they have to accept lower pay. Again, this can undermine the effectivity of the labor market. The ownership impact indicates higher wages in public firms in the first wave, but lower wages in the second. Private firms have to increase their wages to attract workers from the public sector. Due to higher cost pressure, innovation activities could become unattractive. Finally, wages tend to increase with the firm size, and are higher in non-manufacturing sectors such as construction, trade, financial intermediation and social security.

-Table 4 about here-

Besides the aforementioned variables, the hukou status may exert an additional impact on the hourly wage. To investigate this possibility, the urban and migrant data are merged for each period. The hukou status is approximated by a $(0,1)$ dummy variable equal to 1 if the worker has full urban hukou rights and 0 otherwise. As it is demonstrated in Table 4, the availability of 
urban hukou increased wages for the respective workers by 1.35 Yuan per hour in 2007 ( $=0.3$ of the log wage). Therefore, the social discrimination of migrants caused by the limited access to public services offered by the cities has been extended by lower wages. However, the things changed during the recent years, since wage discrimination is not observed in the 2013 survey. On average, migrants earn a wage premium of 0.9 Yuan per hour, i.e. a little more than 7 percent of the median wage. The premium is even larger when the sample is restricted to the low qualified. The implied compensation for the lack of urban hukou rights is likely a driving force of the enormous increase of migrant wages. It is needed to overcome shortages in the migration potential at the Lewis turning point. However, it contributes to further inefficiencies in the labor market. The share of non-productivity related labor costs is on the rise, especially for low-skilled migrants. To avoid further distortions of the wage structure, hukou reforms should be therefore on the agenda.

\section{Conclusions}

Faster urbanization plays a key role in the Chinese economic transformation. However, at the Lewis turning point, the hukou institution constitutes a serious risk to the process, as it restricts the access of migrants to public services offered by cities. To attract further migration, firms started to accept a premium on top of the wage. Therefore, the social discrimination introduced by the hukou system is partially compensated by the internal reactions of market participants, as migrant workers receive additional pay. Based on huge cross sections of private households for 2007 and 2013, this paper provides insights into the size and the development of the wage premium.

Several striking changes have been detected in the wage formation process. This underpins the fact that the Chinese economic transformation occurs very fast. Hourly wages of urban workers exceed those of migrants by 15 percent, as measured by the median. Although the difference is still substantial, it was quite larger a few years ago. A major factor behind the development is the partial removal of hukou disadvantages by the internal market forces. After controlling for the standard wage determinants, such as sex, education, experience and ownership of firms, we find that the premium amounts to 0.9 Yuan or 7 percent of the hourly wage. Because of the premium, the share of non-productivity related labor costs is on the rise, especially for the low-skilled migrants. To avoid further distortions, and to foster further urbanization, hukou status should be unified. Migrants should obtain urban hukou as long as they live in 
cities. They should keep their land use rights when they are in the rural areas. Otherwise, the system could constitute a significant barrier for further urbanization. The removal of institutional bias could restore the link between wages and productivity and improve the allocation of labor. 


\section{References}

Au C-C, Henderson JV (2006a): How migration restrictions limit agglomeration and productivity in China, Journal of Development Economics 80, 350-388.

Au C-C, Henderson JV (2006b): Are Chinese cities too small? Review of Economic Studies 73, 549-576.

Cai F, Du Y (2011): Wage increases, wage convergence, and the Lewis turning point in China, China Economic Review 22, 601-610.

Chan K, Buckingham W (2008): Is China abolishing the hukou system? The China Quarterly 195, 582-606.

Chang KS (1994): Chinese urbanization and development before and after economic reform: A comparative reappraisal, World Development 22, 601-613.

Chen C, Fan CC (2016): China's hukou puzzle: Why don't rural migrants want urban hukou? China Review 16, 9-39.

Cheng T, Selden M (1994): The origin and social consequences of China's hukou system, China Quarterly 139, 644-668.

Côté D, De Resende C (2008): Globalization and inflation: The role of China, Bank of Canada Working Paper 2008-35.

Das M, N'Diaye P (2013): Chronicle of a decline foretold: Has China reached the Lewis turning point? IMF Working Paper 13/26.

Dreger C, Kosfeld R, Zhang Y (2016): Determining minimum wages in China. Do economic factors dominate? IZA Discussion Paper 9716.

Dreger C, Wang T, Zhang Y (2015): Understanding Chinese consumption. The impact of Hukou, Development and Change 46, 1331-1345.

Fu Q, Ren Q (2010): Educational inequality under China's rural-urban divide: The hukou system and return to education, Environment and Planning A 42, 592-610.

Golley J, Meng X (2011): Has China run out of surplus labour? China Economic Review 22, 555572. 
Lee L, Meng X (2009): Why don't more Chinese migrate from the countryside? Institutional constraints and the migration decision, in Meng X, Manning C, Li S, Effendi T (eds): The great migration: Rural-urban migration in China and Indonesia, Edward Elgar.

Liu PW, Xin M, Zhang J (2000): Sectoral gender wage differentials and discrimination in the transitional Chinese economy, Journal of Population Economics 13, 331-352.

Liu Z (2005): Institution and inequality: The hukou system in China, Journal for Comparative Economics 33, 133-157.

Lu Z, Song S (2006): Rural-urban migration and wage determination: The case of Tianjin, China, Chinese Economic Review 17, 337-345.

Meng X, Zhang J (2001): The two-tier labor market in urban China: Occupational segregation and wage differentials between urban residents and rural migrants in Shanghai, Journal of Comparative Economics 29, 485-504.

Naughton B (2007): The Chinese economy: Transitions and Growth, Cambridge, MA, MIT Press.

Li S (2009): Chinese Household Income Project 2002, Ann Arbor Michigan, doi: 10.3886/ICPSR 21741.v1.

United Nations (2014): World Urbanization Prospects: 2014 Revision, New York.

Yang DT (2005): Determinants of schooling returns during transition: Evidence from Chinese cities, Journal of Comparative Economics 33, 244-264.

Yusuf S, Nabeshima K (2006): China's development priorities, World Bank Report, Washington DC.

Zhang DD (2004): Marketization and gender wage differentials, Chinese Journal of Population Science 1, 32-41.

Zhang J, Zhao Y, Park A, Song X (2005): Economic returns to schooling in urban China, 1988 to 2001, Journal of Comparative Economics 33, 730-752.

Zhang L, Sharpe RV, Li S, Darity WA (2016): Wage differentials between urban and rural-urban migrant workers in China, China Economic Review 41, 222-233.

Zhang X, Yang J, Wang S (2011): China has reached the Lewis turning point, China Economic Review 22, 542-554. 
Zhang Z, Wu X (2017): Occupational segregation and earnings attainment of rural migrants in urban China, Social Science Research 61, 57-74. 
Table 1: Distribution of nominal wages in urban labor markets

\begin{tabular}{|l|c|c|c|c|}
\hline & \multicolumn{2}{|c|}{2007} & \multicolumn{2}{c|}{2013} \\
\hline Average & Urbans & Migrants & Urbans & Migrants \\
\hline Std. Deviation. & 13.66 & 6.59 & 18.83 & 14.69 \\
\hline Percentile & 21.13 & 7.73 & 21.48 & 13.33 \\
\hline 10 percent & 3.88 & 2.66 & 5.79 & 6.25 \\
\hline 25 percent & 5.81 & 3.69 & 9.30 & 8.93 \\
\hline 50 percent & 9.97 & 5.40 & 14.42 & 12.50 \\
\hline 75 percent & 16.46 & 7.86 & 22.32 & 17.05 \\
\hline 90 percent & 24.51 & 11.56 & 34.09 & 23.81 \\
\hline
\end{tabular}

Note: Data based on CHIP surveys for 2007 and 2013. Wages are Yuan per hour. 
Table 2: Sample characteristics of urban workers and migrants

\begin{tabular}{|l|c|c|c|c|}
\hline & \multicolumn{2}{|c|}{2007} & \multicolumn{2}{c|}{2013} \\
\hline Sex & Urbans & Migrants & Urbans & Migrants \\
\hline Age & 0.45 & 0.39 & 0.45 & 0.35 \\
\hline Education & 38.7 & 31.6 & 39.4 & 33.6 \\
\hline Experience & 11.7 & 9.1 & 11.8 & 9.1 \\
\hline Contract & 13.7 & 3.4 & 14.7 & 7.6 \\
\hline Industry & 0.43 & 0.60 & 0.50 & 0.88 \\
\hline Owner & 0.18 & 0.20 & 0.22 & 0.31 \\
\hline
\end{tabular}

Note: Data based on CHIP surveys for 2007 and 2013. Age, education (schooling) and professional experience of workers (aged between 15 and 60) are expressed in years. Sex is the share of female workers, contract is the share of short term contracts, industry is the share of workers in the agricultural, energy, and manufacturing sectors, owner is the share of employers in public firms, including government party, and public institutions, state-owned firms and collective enterprises. 
Table 3: Wage regressions for urban workers and migrants

\begin{tabular}{|l|c|c|c|c|}
\hline \multirow{2}{*}{} & \multicolumn{2}{|c|}{2007} & \multicolumn{2}{c|}{2013} \\
\hline Sex & Urbans & Migrants & Urbans & Migrants \\
\hline Age & $0.069(0.024)$ & $0.131(0.023)$ & $0.178(0.015)$ & $0.260(0.014)$ \\
\hline Age^2 & $2.860(1.017)$ & $5.414(0.836)$ & $1.257(0.723)$ & $3.755(0.544)$ \\
\hline Education & $-0.419(0.168)$ & $-0.796(0.122)$ & $-0.154(0.101)$ & $-0.527(0.078)$ \\
\hline Experience & $0.374(0.038)$ & $0.336(0.036)$ & $0.722(0.030)$ & $0.188(0.009)$ \\
\hline Contract & $-0.337(0.033)$ & $-0.075(0.026)$ & $-0.226(0.019)$ & $-0.102(0.009)$ \\
\hline Firm size & $0.000(0.000)$ & $0.026(0.006)$ & $0.031(0.004)$ & $0.025(0.004)$ \\
\hline Owner & $-0.047(0.028)$ & $-0.078(0.033)$ & $0.056(0.018)$ & $0.018(0.029)$ \\
\hline Industry & $0.077(0.028)$ & $-0.136(0.029)$ & $0.042(0.019)$ & $0.064(0.014)$ \\
\hline Constant & $-3.583(2.151)$ & $-8.199(1.416)$ & $-1.922(1.280)$ & $-4.774(0.941)$ \\
\hline \hline Observations & 4711 & 3608 & 6838 & 5622 \\
\hline R-squared & 0.060 & 0.073 & 0.148 & 0.066 \\
\hline
\end{tabular}

Note: Data based on CHIP surveys for 2007 and 2013. Quantile regression, standard errors in parentheses. See text for definitions of variables. 
Table 4: Hukou impact on wages

\begin{tabular}{|l|c|c|}
\hline & 2007 & 2013 \\
\hline Sex & $0.096(0.016)$ & $0.178(0.015)$ \\
\hline Age & $4.252(0.581)$ & $2.553(0.411)$ \\
\hline Education & $-0.619(0.084)$ & $-0.347(0.059)$ \\
\hline Experience & $0.369(0.027)$ & $0.420(0.017)$ \\
\hline Contract & $0.076(0.009)$ & $0.065(0.006)$ \\
\hline Firm size & $-0.229(0.019)$ & $-0.187(0.014)$ \\
\hline Owner & $0.000(0.000)$ & $0.029(0.003)$ \\
\hline Industry & $-0.086(0.019)$ & $0.015(0.014)$ \\
\hline Hukou & $-0.028(0.019)$ & $0.071(0.011)$ \\
\hline Constant & $0.307(0.021)$ & $-0.098(0.013)$ \\
\hline \hline Observations & $-6.227(0.998)$ & $-3.427(0.713)$ \\
\hline R-squared & 8319 & 12460 \\
\hline
\end{tabular}

Note: Data based on CHIP surveys for 2007 and 2013. Quantile regression, standard errors in parentheses. See text for definitions of variables. 